\title{
The effect of provider affiliation with a primary care network on emergency department visits and hospital admissions
}

\author{
Finlay A. McAlister MD MSc, Jeffrey A. Bakal PhD, Lee Green MD MPH, Brad Bahler MD, Richard Lewanczuk MD PhD
}

Cite as: CMAJ 2018 March 12;190:E276-84. doi: 10.1503/cmaj.170385

\begin{abstract}
BACKGROUND: Primary care networks are designed to facilitate access to interprofessional, team-based care. We compared health outcomes associated with primary care networks versus conventional primary care.
\end{abstract}

METHODS: We obtained data on all adult residents of Alberta who visited a primary care physician during fiscal years 2008 and 2009 and classified them as affiliated with a primary care network or not, based on the physician most involved in their care. The primary outcome was an emergency department visit or nonelective hospital admission for a Patient Medical Home indicator condition (asthma, chronic obstructive pulmonary disease, heart failure, coronary disease, hypertension and diabetes) within 12 months.

RESULTS: Adults receiving care within a primary care network $(n=1502916)$ were older and had higher comorbidity burdens than those receiving conventional primary care $(n=1109941)$. Patients in a primary care network were less likely to visit the emergency department for an indicator condition (1.4\% v. $1.7 \%$, mean 0.031 v. 0.035 per patient, adjusted risk ratio [RR] $0.98,95 \%$ confidence interval [Cl] $0.96-0.99)$ or for any cause $(25.5 \% \mathrm{v}$. $30.5 \%$, mean 0.55 v. 0.72 per patient, adjusted RR 0.93, 95\% Cl 0.93-0.94), but were more likely to be admitted to hospital for an indicator condition $(0.6 \% \mathrm{v}$. $0.6 \%$, mean 0.018 v. 0.017 per patient, adjusted RR $1.07,95 \% \mathrm{Cl} 1.03-1.11$ ) or all-cause (9.3\% v. $9.1 \%$, mean 0.25 v. 0.23 per patient, adjusted RR $1.08,95 \% \mathrm{Cl}$ 1.07-1.09). Patients in a primary care network had 169 fewer all-cause emergency department visits and 86 fewer days in hospital (owing to shorter lengths of stay) per 1000 patient-years.

INTERPRETATION: Care within a primary care network was associated with fewer emergency department visits and fewer hospital days. n Alberta, primary care networks were established in 2005 to help facilitate both access to primary care and adoption of the Patient Medical Home model of care, which focuses on chronic disease management, health maintenance and prevention. ${ }^{1,2}$ Although there is no one structure for primary care networks (varying from one co-located clinic to several offices in a geographic area), Alberta Health Services provides funding to each network ( $\$ 50$ per patient in 2008; $\$ 62$ per patient in 2017 in addition to the usual fee-for-service payments to the physicians) for the hire of nonphysician health care providers to help provide coordinated primary health care to a roster of patients. This additional funding cannot be used to support the implementation of electronic medical records - that is the remit of other programs in Alberta that are not tied into participating in primary care networks. Primary care networks vary in the deployment of their nonphysician funding and the frequency with which nonphysician providers see patients. Further details are available at www.health.alberta.ca/services/primary-care-networks.html (last accessed Aug. 31, 2017). Primary care network involvement is voluntary; in 2017 , more than $80 \%$ of primary care physicians in Alberta were affiliated with a primary care network.

The impact of primary care teams on health care utilization is uncertain, with published reports showing benefits that range from negligible ${ }^{3-9}$ to very modest. , $2,10-13$ An early evaluation of the first wave of Alberta primary care networks reported that individuals with newly diagnosed diabetes had better glycemic control and lower rates of emergency department visits or hospital admissions for hyper- or hypoglycemia in 2007 if treated in 1 of the 18 primary care networks at that time. ${ }^{1}$ However, the benefits were small: glycated hemoglobin $\left(\mathrm{HbA}_{1 \mathrm{c}}\right)$ was 0.07 lower and the absolute reduction in emergency department visits or hospital admissions was 0.7 per 1000 patient-months. It is unknown whether benefits would accrue for patients with other chronic diseases managed within primary care networks or whether the improvements would be seen when the primary care networks rolled out beyond the early adopters (who may well practise differently than others). 
We designed this study to examine whether patients of primary care networks had fewer visits to the emergency department and acute care hospital admissions than patients cared for by primary care physicians who are not affiliated with a primary care network ("conventional primary care"). We explored allcause visits or hospital admissions, but also focused on those conditions where primary care is felt to have potentially the greatest impact on patients' health status: asthma, chronic obstructive pulmonary disease, heart failure, coronary disease, hypertension and diabetes (hereafter referred to as Patient Medical Home indicator conditions)..$^{14}$

\section{Methods}

\section{Design and setting}

Alberta has a government-funded health care system that provides more than 4.4 million people with universal access to hospital, emergency department and physician services and is free at the point of care. In this prospective cohort study, we focused on the fiscal years 2008 and 2009, being the period when approximately half of Alberta primary care physicians were affiliated with primary care networks.

\section{Data sources}

This study used the Discharge Abstract Database, which records the admission date, discharge date, most responsible diagnosis and up to 24 other diagnoses for all acute care hospital admissions; the Ambulatory Care Database, which records all patient visits to the offices of hospital-based physicians or to emergency departments, with coding for of up to 10 conditions, including the most responsible diagnosis; the Physician Claims Database, which tracks all physician claims for outpatient services and includes up to 3 diagnoses per encounter; and the Alberta Health Care Insurance Registry.

\section{Study cohort and identification of exposure}

We identified all Albertans aged 20 years or older who were seen by a primary care physician at least once in fiscal years 2008 or 2009 . We stratified them into affiliation with a primary care network or not, based on the physician who provided most of their outpatient primary care in the 2 years of the study. Alberta Health renews its list of physicians affiliated with a primary care network each fiscal year. We assigned each patient an index date (their first visit to a primary care physician during the study period) and analyzed all events in the first year after the index date.

\section{Covariates}

We used International Classification of Diseases, 9th Revision (ICD-9) and 10th Revision (ICD-10) codes from the Discharge Abstract Database for any hospital admissions, any emergency department visits and any outpatient visits in the 2 years before the index visit, to identify comorbidities. The validity of diagnoses captured in these data sets using 2 hits in the outpatient or emergency department records or 1 hit in the Discharge Abstract Database has been established in Alberta. ${ }^{15,16}$

\section{Outcomes}

Our primary outcome was the proportion of patients having an emergency department visit or hospital admission for nonelective acute care for a most responsible diagnosis linked to any of the Patient Medical Home indicator conditions (Appendix 1, available at www.cmaj.ca/lookup/suppl/doi:10.1503/cmaj.170385/-/DC1) these are the same as the Ambulatory Care Sensitive Conditions defined by the Canadian Institute for Health Information, but do not include epilepsy. Secondary outcomes included the proportion of patients with an all-cause emergency department visit or hospital admission, the individual components of the primary outcome, hospital length of stay for those hospitalized, 30-day readmission rates after hospital discharge and 30-day repeat emergency department visits, using previously published definitions. ${ }^{17}$ All events for each patient were counted, but visits to the emergency department that resulted in a hospital admission during the same encounter or transfers between emergency departments or hospitals in the same episode of care were counted as only 1 event.

In order to further explore rates of readmission to hospital, emergency department visits, or death for patients who were recently admitted to hospital and who were actively engaged with their primary care physician, we conducted a sensitivity analysis for those patients who had been discharged within 90 days of their index visit to a physician as an outpatient. This cohort was divided into 3 risk groups based on their comorbidity level (a summary score based on clinical risk groupings for all hospital admissions in the previous year). Low-risk groups are defined as those with a total comorbidity factor of $0 \%-24 \%$; moderate-risk groups with comorbidity scores of $25 \%-50 \%$; and high-risk groups as those with $>50 \%$ comorbidity levels in the Canadian Institute for Health Information Discharge Abstract Database file.

\section{Statistical analyses}

We compared patient baseline characteristics and examined the association between care through a primary care network and outcomes using a series of zero-inflated Poisson models with total emergency department utilization and hospital admission for Patient Medical Home indicator conditions and all causes. Additionally, we created a series of logistic regression models for the individual indicator conditions. In the first set of models for each analysis, the covariates we adjusted for included age, sex and all of the clinical comorbidities listed in Table 1 . In the second set of models, we included health system factors including the number of visits with a primary care physician, the geographic zone in which the primary care network was situated (the province is divided into 5 zones within Alberta Health Services) and socioeconomic factors (whether the patient had a rural or urban residence and the postal code-based Pampalon material and social deprivation index: www.cihi.ca/en/deprivation-in -canadian-cities-an-analytical-tool, last accessed Aug. 31, 2017). ${ }^{18}$

We accounted for clustering within primary care networks by incorporating the primary care network identification number as a random-effect variable. We also conducted a sensitivity analysis in which we included only patients with at least 2 visits to a primary care physician in the previous year and we compared 
Table 1 (part 1 of 2): Characteristics of patients cared for by primary care physicians in Alberta 2008-2010

No. of patients in a primary care network ${ }^{*}$

\section{Characteristic}

Age, mean \pm SD

Male

Rural residence

Charlson Comorbidity Index score, mean \pm SD

Median number of physician visits in previous year (IQR)

Patient Medical Home indicator conditions

Diabetes
Heart failure
Hypertension
Chronic obstructive pulmonary disease
Asthma
Coronary artery disease (previous myocardial
infarction, coronary artery bypass graft,
percutaneous intervention, or chronic angina)
Other chronic conditions

Anemia

Cerebrovascular disease

Renal disease

Cancer

Peripheral vascular disease

Dementia

Atrial fibrillation

Cardiogenic shock

Stroke

Pneumonia

Protein calorie malnutrition

Hemiparesis or paralysis

Solid tumour

Trauma

Psychiatric disorder

Severe liver disease

Fluid imbalance

Skin ulcer

Gastrointestinal bleed

Nephritis

Nonmetastatic cancer

Drug abuse

Depression

Arthritis

HIV (\%) $\dagger$

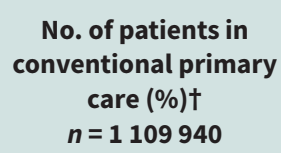

No. of patients in conventional primary care $(\%) \dagger$ $n=1109940$ Standardized difference $\ddagger$

$n=1502916$

$44.0 \pm 19.5$
$548047(49.4)$
$174291(15.70)$
$0.32 \pm 1.02$
$2(1-6)$

$-0.11$

$46.1 \pm 18.4$

$684482(45.4)$

218064 (14.51)

$0.34 \pm 1.01$

$3(1-6)$

85857 (5.71)

14134 (0.94)

219082 (14.58)

87324 (5.81)

47554 (3.16)

23029 (1.53)

36314 (2.42)

15957 (1.06)

9803 (0.65)

16611 (1.11)

9004 (0.60)

$10015(0.67)$

28644 (1.91)

17621 (1.17)

$12850(0.86)$

24818 (1.65)

$507(0.03)$

$3752(0.25)$

$4527(0.30)$

286012 (19.03)

224109 (14.91)

$1210(0.08)$

21603 (1.44)

2658 (0.18)

8727 (0.58)

$6458(0.43)$

24096 (1.60)

24292 (1.62)

174485 (11.61)

15172 (1.01)

$712(0.05)$
57409 (5.17)

10148 (0.91)

140726 (12.68)

62008 (5.60)

32035 (2.89)

15874 (1.43)

$-0.02$

0.00

$-0.06$

$-0.01$

$-0.02$

$-0.02$

24056 (2.17)

$-0.02$

$10746(0.97)$

$-0.01$

7458 (0.67)

0.00

11797 (1.06)

0.00

5681 (0.51)

$-0.01$

6664 (0.60)

$-0.01$

15752 (1.42)

$-0.04$

$8217(0.74)$

$-0.04$

8547 (0.77)

$-0.01$

18674 (1.68)

0.00

$281(0.03)$

0.00

$2866(0.26)$

0.00

$4082(0.37)$

0.01

221549 (19.96)

0.02

141004 (12.70)

$-0.06$

1032 (0.09)

0.00

15920 (1.43)

0.00

1669 (0.15)

0.01

$5927(0.53)$

$-0.01$

5141 (0.46)

0.01

15855 (1.43)

$-0.01$

22990 (2.07)

0.03

107348 (9.67)

$-0.06$

$9315(0.84)$

$-0.02$

$576(0.05)$

0.00 
Table 1 (part 2 of 2): Characteristics of patients cared for by primary care physicians in Alberta 2008-2010

\begin{tabular}{|c|c|c|c|}
\hline Characteristic & $\begin{array}{c}\text { No. of patients in a } \\
\text { primary care network } \\
\text { (\%)† } \\
n=1502916\end{array}$ & $\begin{array}{c}\text { No. of patients in } \\
\text { conventional primary } \\
\text { care }(\%) \dagger \\
n=1109940\end{array}$ & Standardized difference $\ddagger$ \\
\hline Pampalon Material Deprivation Index quintiles,§ \% & & & 0.18 \\
\hline 1 & 16.87 & 21.26 & \\
\hline 2 & 16.33 & 20.66 & \\
\hline 3 & 19.38 & 19.07 & \\
\hline 4 & 20.28 & 17.65 & \\
\hline 5 (most deprived) & 22.56 & 17.93 & \\
\hline Pampalon Social Deprivation Index quintiles,ฯ \% & & & 0.07 \\
\hline 1 & 12.92 & 16.23 & \\
\hline 2 & 15.88 & 17.32 & \\
\hline 3 & 19.26 & 19.77 & \\
\hline 4 & 23.56 & 23.05 & \\
\hline 5 (most deprived) & 23.77 & 20.2 & \\
\hline
\end{tabular}

results in the 2 cohorts (primary care network v. conventional primary care) matched by age, sex and geographic zone and Charlson Comorbidity Index score. As we did not have information on date of death (only whether a patient was alive or not during each fiscal year), we explored the impact of mortality as a competing risk by conducting a sensitivity analysis that excluded any patients who had died or emigrated during the study period.

\section{Ethics approval}

This retrospective cohort study received ethics approval from the University of Alberta (Pro00048445) with a waiver of informed consent because we were using de-identified data.

\section{Results}

In fiscal years 2008 and 2009, there were 30 primary care networks in Alberta involving 1709 physicians with 2257111 patients on their rosters: 1502916 Albertan adults received outpatient care from a primary care physician affiliated with a primary care network, and 1109941 received conventional primary care. Patients in a primary care network were older (46 v. 44 yr), had more chronic conditions, had higher comorbidity burdens and saw their primary care physician more frequently (Table 1).

Patients receiving outpatient care from physicians affiliated with a primary care network were less likely to present to an emergency department for any cause $(25.5 \%$ v. $30.5 \%$, absolute risk difference $5.0 \%$, number needed to treat 20 ; mean emer- gency department visits 0.55 v. 0.72 per patient; both $p<0.001$ ) or for an indicator condition ( $1.4 \%$ v. $1.7 \%$, mean emergency department visits 0.03 v. 0.04 per patient, both $p<0.001$ ).

Adjusting for socioeconomic status and health system factors (frequency of visits, rural or urban residence, health authority zone) in the Poisson models (in addition to patient demographics and clinical covariates) resulted in less pronounced but still significant associations between primary care network affiliation and lower risk of emergency department visits for any cause or for indicator conditions (Table 2). Similar significant associations were also seen in the matched cohort analysis. Including "outpatient visits with an internal medicine specialist" did not alter the magnitude of the associations (data not shown). The association between receiving care from a physician affiliated with a primary care network and lower rates of visits to emergency departments or hospital admissions was significant for 4 of the indicator conditions in the multivariable model adjusting for demographics and clinical comorbidities, but in only 2 (lower for hypertension, higher for coronary artery disease) after also adjusting for health system use and socioeconomic status (Figure 1).

Hospital admissions were more likely for patients in a primary care network, both for indicator conditions ( $0.6 \%$ v. $0.6 \%$, and mean 0.018 v. 0.017 per patient, adjusted risk ratio [RR] 1.07, 95\% confidence interval $[\mathrm{Cl}] 1.03-1.11)$ and for any cause $(9.3 \% \mathrm{v}$. $9.1 \%$, mean 0.25 v. 0.23 per patient, adjusted RR $1.08,95 \% \mathrm{Cl}$ 1.07-1.09). This excess risk persisted even after excluding 
Table 2: Twelve-month outcomes for patients cared for by primary care physicians in Alberta 2008-2010

\section{No. of events in patients in a \\ primary care \\ network ${ }^{\star}$}

Outcomes

\section{No. of events in \\ patients in \\ conventional primary care \\ $n=1109940$}

Clinically adjusted RR† (95\% Cl)
Matched $\S$ cohort analysis with conditional RR $(95 \% \mathrm{CI})$

\section{Emergency department visit}

Patient Medical Home indicator conditions

Patients with event
Total events
Mean per patient
All-cause

All-cause

Patients with event

Total events

Mean per patient

\section{Hospital admission}

Patient Medical Home indicator conditions

Patients with event
Total events
Mean per patient

All-cause

Patients with event

Total events

Mean per patient $n=1502916$

21655 (1.4\%)

29679

0.031

$n=1502916$

382819 (25.5\%)

830260

0.55

$$
n=1502916
$$

8557 (0.57\%)

11072

0.018

$n=1502916$

139394 (9.3\%)

155631

0.25 $n=1109940$

$18830(1.7 \%)$

26160

0.035

$n=1109940$

337983 (30.5\%)

800039

0.72

$n=1109940$

$6876(0.62 \%)$

8769

1.07 (1.03-1.10)

$0.93(0.90-0.96)$

$1.07(1.03-1.11)$

$0.95(0.92-0.98)$

0.017

$n=1109940$

101068 (9.1\%)

$$
121929
$$

$1.06(1.05-1.07)$

$0.98(0.97-0.99)$

1.08 (1.07-1.09)

$1.11(1.10-1.12)$

0.23

After excluding patients who died or emigrated from Alberta during the study period

\begin{tabular}{|c|c|c|c|c|c|c|}
\hline $\begin{array}{l}\text { Patient Medical Home } \\
\text { indicator conditions }\end{array}$ & $n=1466259$ & $n=1067579$ & & & & \\
\hline Patients with event & $19171(1.3 \%)$ & $16444(1.5 \%)$ & & & & \\
\hline Total events & 25625 & 22384 & $0.90(0.88-092)$ & $0.81(0.79-0.82)$ & $0.96(0.94-0.99)$ & $0.86(0.84-0.88)$ \\
\hline Mean per patient & 0.025 & 0.031 & & & & \\
\hline All-cause & $n=1466259$ & $n=1067579$ & & & & \\
\hline Patients with event & 366475 (25\%) & $319750(30.0 \%)$ & & & & \\
\hline Total events & 783994 & 749799 & $0.84(0.84-0.84)$ & $0.78(0.77-0.79)$ & $0.92(0.92-0.93)$ & $0.81(0.80-0.81)$ \\
\hline Mean per patient & 0.53 & 0.70 & & & & \\
\hline \multicolumn{7}{|l|}{ Hospital admission } \\
\hline $\begin{array}{l}\text { Patient Medical Home } \\
\text { indicator conditions }\end{array}$ & $n=1466259$ & $n=1067579$ & & & & \\
\hline Patients with event & $6797(0.5 \%)$ & $5116(0.5 \%)$ & & & & \\
\hline Total events & 8248 & 6238 & $1.10(1.05-1.14)$ & $0.90(0.87-0.94)$ & $1.04(1.00-1.09)$ & $1.00(0.96-1.04)$ \\
\hline Mean per patient & 0.014 & 0.012 & & & & \\
\hline All-cause & $n=1466259$ & $n=1067579$ & & & & \\
\hline Patients with event & $127933(8.7 \%)$ & $88885(8.3 \%)$ & & & & \\
\hline Total events & 135284 & 101762 & $1.09(1.08-1.10)$ & $0.99(0.99-1.00)$ & $1.08(1.07-1.10)$ & $1.11(1.10-1.12)$ \\
\hline Mean per patient & 0.22 & 0.20 & & & & \\
\hline
\end{tabular}
Emergency department visit 
patients who had died during the study period $(4.7 \%$ of those cared for by physicians affiliated with a primary care network and $8.4 \%$ of those cared for in conventional primary care) and those who emigrated out of province during the study period (1.3\% and $2.0 \%$, respectively). All-cause hospital admissions (adjusted RR $1.11,95 \% \mathrm{Cl} 1.10-1.12$ ) remained significantly higher for patients in a primary care network, and all-cause emergency department visits remained significantly lower (adjusted RR 0.96, 95\% Cl 0.95-0.96).

The number of days in hospital (986 v. 1072, $p<0.0001$ ) and the number of emergency department visits (552 v. 721, $p<0.0001$ ) per 1000 patient-years were significantly lower for patients in a primary care network. Mean length of stay for patients in hospital (6.99 v. $7.52 \mathrm{~d}, p=0.001)$, mean inpatient cost per patient ( $\$ 1102$ v. $\$ 1254, p=0.001$ ), 30-day readmissions (7.8\% v. 9.0\%, adjusted odds ratio [OR] 0.86 [95\% Cl 0.83-8.88]), and repeat emergency department visits within 30 days $(24.5 \% \mathrm{v}$. $29.1 \%$, adjusted OR 0.79 [0.78-0.80]) were all lower for patients in a primary care network. Restricting this analysis to only those patients who had been admitted to hospital within 90 days of their index visit to primary care as an outpatient confirmed that 30 -day rates of readmission or mortality ( $4.1 \%$ v. $6.3 \%$, adjusted OR $0.64,95 \% \mathrm{Cl} 0.60-0.68)$ or emergency department visits (43.3\% v. 46.8\%, adjusted OR 0.94, 95\% Cl 0.92-0.97) were lower for patients actively engaged with a primary care network, with the magnitude of difference being greatest for patients with more comorbidities (Table 3).

Of the emergency department visits, most (56.7\% for patients in a primary care network and $55.9 \%$ for patients in conventional primary care) occurred outside of normal working hours (08:00-17:00 Monday to Friday). The association between affiliation with a primary care network and lower emergency department visit rates was similar whether looking at after-office hours (RR $0.80,95 \% \mathrm{Cl} 0.79-0.80$ ) or during-office hours (RR $0.78,95 \%$ $\mathrm{Cl} 0.77-0.78)$.

\section{Interpretation}

We found that patients who received outpatient care from physicians affiliated with primary care networks were significantly less likely to present to an emergency department for any reason or for Patient Medical Home indicator conditions, suggesting improved access to primary care. Although patients of physicians affiliated with primary care networks were slightly more likely to be admitted to hospital for nonelective causes, lengths of stay were shorter, such that patients affiliated with a primary care network spent 86 fewer days in hospital per 1000 patient-years. After adjustment for health system use, socioeconomic status and region, as well as clinical covariates, the only Patient Medical Home indicator conditions with statistically significant results

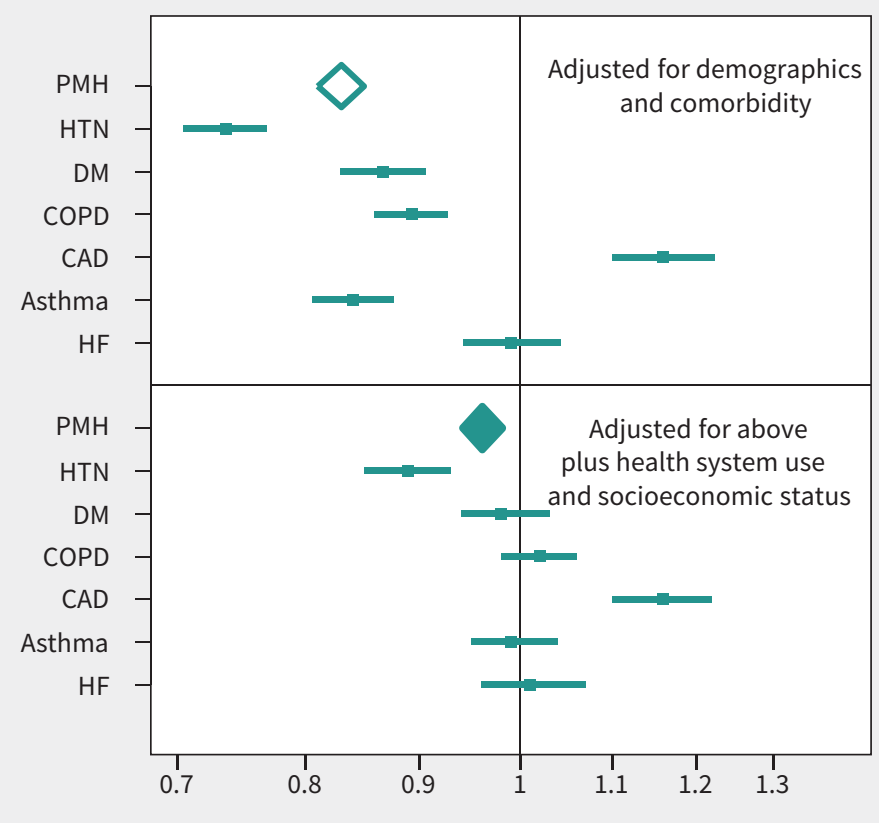

Adjusted odds ratio

Figure 1: Association between affiliation with a primary care network and health care utilization (emergency department visits or hospital admissions) for Patient Medical Home indicator conditions as the most responsible diagnosis. Comorbidity adjustment was for the Charlson Comorbidity Index score. Note: $\mathrm{CAD}=$ coronary artery disease, $\mathrm{COPD}=$ chronic obstructive pulmonary disease, $\mathrm{DM}=$ diabetes mellitus, $\mathrm{HF}=$ heart failure, $\mathrm{HTN}=$ hypertension, $\mathrm{PMH}=$ Patient Medical Home indicator conditions. 
were fewer emergency department visits or hospital admissions for hypertension, but more for chronic coronary disease (not acute coronary syndromes). We suspect this reflects increased frequency of contact (allowing more frequent checks of blood pressure and thus better hypertension control v. more frequent contact, which increases the likelihood of a patient reporting chest pain, leading to a recommendation to attend an emergency department), but it may also just be chance. Moreover, 30-day readmission rates and repeat emergency department visits were all significantly lower after hospital discharge in patients affiliated with primary care networks.

\section{Comparison with other studies}

Another Canadian province, Ontario, has taken a different tack in its efforts at primary care reform. Its analysis of family health teams (akin to Alberta primary care networks with interprofessional teams and blended capitation physician payments) reported no statistically significant differences in emergency department visits or hospital admission rates for chronic conditions compared with 4 other primary care models in the same province between 2004 and 2012. ${ }^{19}$ Further research that focuses on process differences between Ontario family health teams and Alberta primary care networks is needed to explore the reasons for these differential effects.

On the other hand, our findings are similar to those reported by Intermountain Healthcare in Utah, where team-based care was associated with significantly lower rates of all-cause emergency department visits (incidence rate ratio [IRR] 0.77, 95\% Cl 0.74-0.80) and ambulatory care-sensitive emergency department visits or hospital admissions (IRR $0.77,95 \% \mathrm{Cl} 0.70-0.85$ ) compared with traditional primary care practices, with similar absolute differences to those we observed (5.4\% absolute reduction in emergency department visits). ${ }^{10}$ However, unlike in our study, they found that the rate of all-cause hospital admissions was significantly lower

Table 3: Thirty-day outcomes of patients seeing a primary care physician in Alberta 2008-2010 within 90 days of hospital discharge

\begin{tabular}{|c|c|c|c|}
\hline Characteristic & $\begin{array}{l}\text { No. of patients in a primary } \\
\text { care network }{ }^{\star}(\%) \dagger\end{array}$ & $\begin{array}{l}\text { No. of patients in } \\
\text { conventional } \\
\text { primary care }(\%) \dagger\end{array}$ & $\begin{array}{l}\text { Adjusted OR } \\
(95 \% \mathrm{CI}) \ddagger\end{array}$ \\
\hline All patients & $n=41056$ & $n=57087$ & \\
\hline $30 \mathrm{~d}$ readmission or death & $2351(4.1)$ & $2606(6.3)$ & $0.64(0.60-0.68)$ \\
\hline $30 \mathrm{~d}$ readmission & $2331(4.1)$ & $2420(5.9)$ & $0.70(0.65-0.74)$ \\
\hline $30 \mathrm{~d}$ death after discharge & $45(0.1)$ & $444(1.1)$ & $0.07(0.05-0.09)$ \\
\hline $30 \mathrm{~d}$ ED visit after discharge & $24721(43.3)$ & 19206 (46.78) & $0.94(0.92-0.97)$ \\
\hline $\begin{array}{l}\text { Patients with the highest } \\
\text { comorbidity load }(>50 \%)\end{array}$ & $n=4268(7.5)$ & $n=3556(8.7)$ & \\
\hline $30 \mathrm{~d}$ readmission or death & $378(8.9)$ & $499(14.0)$ & $0.59(0.51-0.68)$ \\
\hline $30 \mathrm{~d}$ readmission & $367(8.6)$ & $429(12.1)$ & $0.69(0.59-0.80)$ \\
\hline $30 \mathrm{~d}$ death after discharge & $16(0.4)$ & $153(4.3)$ & $0.08(0.05-0.13)$ \\
\hline $30 \mathrm{~d}$ ED visit after discharge & $2257(52.9)$ & $1943(54.6)$ & $0.98(0.89-1.07)$ \\
\hline $\begin{array}{l}\text { Patients with } 25 \%-50 \% \\
\text { comorbidity load }\end{array}$ & $n=4580(8.0)$ & $n=3654(8.9)$ & \\
\hline $30 \mathrm{~d}$ readmission or death & $300(6.6)$ & $339(9.3)$ & $0.67(0.57-0.79)$ \\
\hline $30 \mathrm{~d}$ readmission & $298(6.5)$ & $312(8.5)$ & $0.73(0.62-0.87)$ \\
\hline $30 \mathrm{~d}$ death after discharge & $8(0.2)$ & $77(2.1)$ & $0.08(0.04-0.16)$ \\
\hline $30 \mathrm{~d}$ ED visit after discharge & $2292(50.0)$ & $1872(51.3)$ & $1.00(0.92-1.10)$ \\
\hline $\begin{array}{l}\text { Patients with the lowest } \\
\text { comorbidity load }(<25 \%)\end{array}$ & $n=48239(84.5)$ & $n=33846(82.4)$ & \\
\hline $30 \mathrm{~d}$ readmission or death & $1673(3.5)$ & $1768(5.2)$ & $0.67(0.62-0.72)$ \\
\hline $30 \mathrm{~d}$ readmission & $1666(3.5)$ & $1679(5.0)$ & $0.71(0.66-0.76)$ \\
\hline 30 d death after discharge & $21(0.04)$ & $214(0.6)$ & $0.07(0.04-0.10)$ \\
\hline $30 \mathrm{~d}$ ED visit after discharge & $20172(41.8)$ & $15391(45.5)$ & $0.93(0.91-0.93)$ \\
\hline
\end{tabular}


(IRR 0.89, 95\% Cl 0.85-0.94, absolute risk difference 1.2 per 100 person-years). Although this may be attributable to the substantial clinical decision support technology and standardized chronic disease management pathways in their system, it may also be because they had a higher proportion of hospital admissions owing to Patient Medical Home indicator conditions than we did (one-sixth v. one-sixteenth in our cohort). Our proportion of admissions that are related to Patient Medical Home indicator conditions is closer to that reported by the Seattle Group Health Cooperative, ${ }^{12}$ which found no significant difference in all-cause hospital admissions (but a $29 \%$ relative reduction in all-cause emergency department visits) with a team-based primary care model similar to Alberta's Primary Care Networks.

Although the Utah, ${ }^{10}$ Seattle $^{13}$ and Ontario ${ }^{20}$ groups reported higher rates of some quality-of-care measures in team-based practices, it is important to note that not all process measures were improved in any of the settings - for example, blood pressure control rates were lower with team-based care in Utah and cancer screening rates were lower in Ontario. We were unable to examine quality of care in this study, although such an evaluation is currently ongoing in Alberta.

It is unclear to what extent our findings may be a result of better continuity of care in primary care networks. Primary care studies in multiple settings (including Europe, the United Kingdom, the United States and Australia) have shown that patients with greater physician continuity are less likely to use emergency departments or require hospital admissions, especially patients with chronic conditions or multiple comorbidities. ${ }^{21-24}$ Future studies should evaluate continuity metrics for patients treated in primary care networks, particularly in light of studies suggesting that older patients see a median of 2 primary care physicians and 5 specialists per year. ${ }^{25}$

\section{Limitations}

Although we were able to analyze all health care interactions for an entire Canadian province, there are some limitations to our study. Most importantly, we cannot infer causation, as unmeasured confounders (including patient health behaviours and provider demographics) may have differed between patients treated in primary care networks and conventional primary care. Second, although the amount of nonphysician team care provided likely differed between primary care networks, we do not have data on the frequency of visits to nonphysician health care providers and thus cannot comment on the incremental benefits of particular care elements. Third, we were unable to evaluate timeliness of access or patient satisfaction, and without access to actual laboratory values or physical measures, we cannot comment on the quality of care delivered to this cohort of patients. Fourth, we have no information on whether physicians affiliated with a primary care network were more likely to have electronic medical records; nor do we have any data on the quality of communication or coordination between different members of the health care team in primary care network practices. Finally, as the data were provided to us by Alberta Health in deidentified fashion, with the primary care network designation assigned to the patient file without details of their specific provider(s), we cannot create propensity scores for provider fac- tors or adjust for potential clustering at the level of individual physicians, or the length of time particular physicians have been practising in a primary care network.

\section{Conclusion}

Our analysis suggests that a province-wide program to promote team-based primary care is a feasible and effective way to reduce use of emergency departments for Patient Medical Home indicator conditions or for any cause (a potential marker of improved access to care). Although physician pay for performance is often emphasized in efforts to reform primary care, ${ }^{26}$ the potential impact on the population seen with the Alberta primary care network natural experiment (169 fewer emergency department visits and 86 fewer hospital days per 1000 patient-years) is larger than has been seen with incentive payments for primary care physicians in various settings. ${ }^{27-29}$ Although the primary care network model holds substantial promise, a similar model in Ontario was not associated with similar effects. Thus, further research is required to explore the variation in implementation and process between Ontario family health teams and Alberta primary care networks, which may account for these differences.

\section{References}

1. Manns BJ, Tonelli M, Zhang J, et al. Enrolment in primary care networks: impact on outcomes and processes of care for patients with diabetes. CMAJ 2012; 184:E144-52.

2. Jackson GL, Powers BJ, Chatterjee R, et al. Improving patient care. The patientcentered medical home: a systematic review. Ann Intern Med 2013;158:169-78.

3. Smith SM, Wallace E, O'Dowd T, et al. Interventions for improving outcomes in patients with multimorbidity in primary care and community settings. Cochrane Database Syst Rev 2016;3:CD006560.

4. Hogg W, Lemelin J, Dahrouge S, et al. Randomized controlled trial of anticipatory and preventive multidisciplinary team care: for complex patients in a community-based primary care setting. Can Fam Physician 2009;55:e76-85.

5. Katon WJ, Lin EHB, Von Korff M, et al. Collaborative care for patients with depression and chronic illnesses. N Engl J Med 2010;363:2611-20.

6. Sommers LS, Marton KI, Barbaccia JC, et al. Physician, nurse and social worker collaboration in primary care for chronically ill seniors. Arch Intern Med 2000;160: 1825-33.

7. Boult C, Reider L, Leff B, et al. The effect of guided care teams on the use of health services: results from a cluster-randomized controlled trial. Arch Intern Med 2011;171: 460-6.

8. Friedberg MW, Schneider EC, Rosenthal MB, et al. Association between participation in a multipayer medical home intervention and changes in quality, utilization, and costs of care. JAMA 2014;311:815-25.

9. Werner RM, Duggan M, Duey K, et al. The patient-centered medical home: an evaluation of a single private payer demonstration in New Jersey. Med Care 2013;51: 487-93.

10. Reiss-Brennan B, Brunisholz KD, Dredge C, et al. Association of integrated teambased care with health care quality, utilization, and cost. JAMA 2016;316:826-34.

11. Rosenthal MB, Friedberg MW, Singer SJ, et al. Effect of a multipayer patient-centered medical home on health care utilization and quality: the Rhode Island chronic care sustainability initiative pilot program. JAMA Intern Med 2013;173:1907-13.

12. Reid RJ, Coleman K, Johnson EA, et al. The Group Health medical home at year two: cost savings, higher patient satisfaction, and less burnout for providers. Health Aff (Millwood) 2010;29:835-43.

13. Riverin BD, Li P, Naimi Al, et al. Team-based versus traditional primary care models and short-term outcomes after hospital discharge. CMAJ 2017;189:E585-93.

14. Annis Emeott A, Markovitz A, Mason MH, et al. Four year evolution of a large, state-wide patient-centred medical home designation program in Michigan. Med Care 2013;51:846-53. 
15. Quan H, Li B, Saunders LD. IMECCHI Investigators. Assessing validity of ICD-9-CM and ICD-10 administrative data in recording clinical conditions in a unique dually coded database. Health Serv Res 2008;43:1424-41.

16. Tonelli M, Wiebe N, Fortin M, et al.; Alberta Kidney Disease Network. Methods for identifying 30 chronic conditions: application to administrative data. BMC Med Inform Decis Mak 2015;15:31.

17. McAlister FA, Bakal J, Majumdar SR, et al. Safely and effectively reducing inpatient length of stay: a controlled study of the General Internal Medicine Care Transformation Initiative. BMJ Qual Saf 2014;23:446-56.

18. Pampalon R, Hamel D, Gamache P, et al. An area-based material and social deprivation index for public health in Québec and Canada. Can J Public Health 2012;103(Suppl 2):S17-22.

19. Glazier RH, Hutchison B, Kopp A. Comparison of family health teams to ther Ontario primary care models, 2004/05 to 2011/12. Toronto: Institute for Clinical Evaluative Sciences; 2015.

20. Kiran T, Kopp A, Moineddin R, et al. Longitudinal evaluation of physician payment reform and team-based care for chronic disease management and prevention. CMAJ 2015;187:E494-502.

21. Hussey PS, Schneider EC, Rudin RS, et al. Continuity and the costs of care for chronic disease. JAMA Intern Med 2014;174:742-8.
22. van Walraven $\mathrm{C}$, Oake $\mathrm{N}$, Jennings $\mathrm{A}$, et al. The association between continuity of care and outcomes: a systematic and critical review. J Eval Clin Pract 2010;16:947-56.

23. Nyweide DJ, Anthony DL, Bynum JPW, et al. Continuity of care and the risk of preventable hospitalization in older adults. JAMA Intern Med 2013;173:1879-85.

24. Weir DL, McAlister FA, Majumdar SR, et al. The interplay between continuity of care, multimorbidity, and health outcomes in patients with diabetes. Med Care 2016;54:386-93.

25. Pham HH, Schrag D, O'Malley AS, et al. Care patterns in Medicare and their implications for pay for performance. N Engl J Med 2007;356:1130-9.

26. Nuckols TK. With the Merit-Based Incentive Payment System, pay for perfor mance is now national policy. Ann Intern Med 2017;166:368-9.

27. Lavergne MR, Law MR, Peterson S, et al. A population-based analysis of incentive payments to primary care physicians for the care of patients with complex disease. CMAJ 2016;188:E375-83.

28. Harrison MJ, Dusheiko M, Sutton M, et al. Effect of a national primary care pay for performance scheme on emergency hospital admissions for ambulatory care sensitive conditions: controlled longitudinal study. BMJ 2014;349:g6423.

29. Houle SK, McAlister FA, Jackevicius C, et al. Does performance-based remuneration for individual health care practitioners affect patient care? A systematic review. Ann Intern Med 2012;157:889-99.
Competing interests: Brad Bahler and Richard Lewanczuk hold positions with Alberta Health Services. No other competing interests were declared.

This article has been peer reviewed.

Affiliations: Division of General Internal Medicine (McAlister) and Patient Health Outcomes Research and Clinical Effectiveness Unit (McAlister, Bakal), Alberta SPOR Support Unit Data Platform; Department of Family Medicine (Green); Department of Medicine (Lewanczuk), University of Alberta and Primary Health Care, Alberta Health Services (Bahler), Edmonton, Alta.

Contributors: Finlay McAlister was responsible for study conception and the first draft of the manuscript. Jeffrey Bakal assisted with the acquisition of data and analysis. All authors contributed to the study design, interpretation of analyses and revision of the manuscript. All of the authors gave final approval of the version to be published and agree to be accountable for all aspects of the work.
Funding: No funding was received for this study. Infrastructure support was provided by the Alberta SPOR Support Unit Data Platform. Finlay McAlister holds the University of Alberta Chair in Cardiovascular Outcomes Research. These organizations were not involved in the design and conduct of the study; collection, management, analysis and interpretation of the data; preparation, review or approval of the manuscript; or decision to submit the manuscript for publication.

Acknowledgements: This study is based in part on data provided by Alberta Health and Alberta Health Services. The interpretation and conclusions contained herein are those of the researchers and do not necessarily represent the views of the Government of Alberta or Alberta Health Services. Neither the Government of Alberta nor Alberta Health Services expresses any opinion in relation to this study.

Accepted: Oct. 23, 2017

Correspondence to: Finlay McAlister, Finlay.McAlister@ualberta.ca 